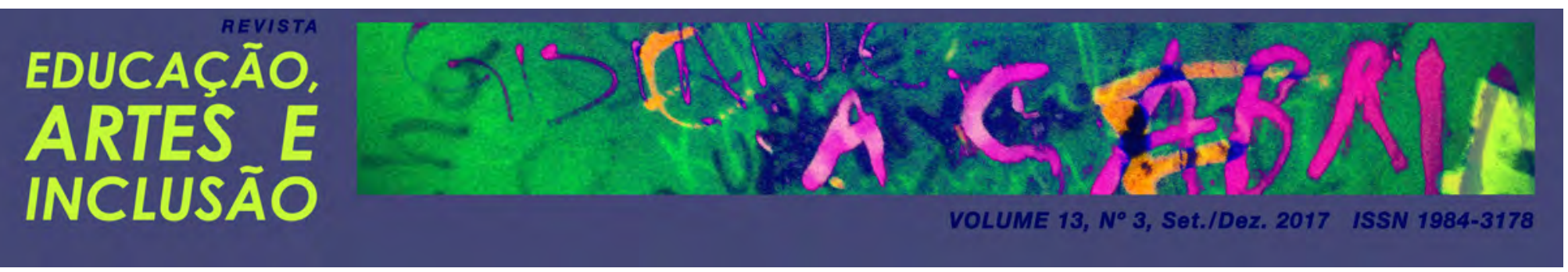

\title{
CONSIDERAÇÕES SOBRE A FORMAÇÃO DOCENTE NA PERSPECTIVA DA INCLUSÃO ESCOLAR
}

\section{CONSIDERATIONS ABOUT THE TEACHER'S EDUCATION IN THE PERSPECTIVE OF SCHOOL INCLUSION}

DOI: http://dx.doi.org/10.5965/1984317813032017099

Patrícia Cardoso Macedo do Amaral Araujo - Universidade Federal Rural do Rio de Janeiro

\begin{abstract}
RESUMO
Este artigo contempla uma pesquisa bibliográfica no campo da Educação, mais especificamente da área da Educação Especial, com o objetivo compreender como vem se dando a formação docente no Brasil a partir da perspectiva da educação inclusiva. Tendo em vista tais questões, a pesquisa bibliográfica, contou com referencial teórico de autores como Fernando Becker, Edgar Morin e Boaventura de Sousa Santos. Foi empregada ainda a perspectiva histórico-cultural de Vygotsky e de autores que dialogam com essa abordagem a fim de encontrar em seus conceitos aporte para as reflexões aqui apresentadas. $\mathrm{O}$ estudo indicou que a formação de professores, tanto a inicial como a continuada, deve estar apta para produzir conhecimentos voltados para a prática docente que aprimorem respostas para atender as demandas da diversidade dos alunos presentes na escola. A indissociabilidade da teoria e da prática é o caminho para formar professores capacitados para o pensamento crítico e reflexivo de sua ação pedagógica e criar possibilidades para atender, da melhor maneira, as demandas existentes no cotidiano escolar.
\end{abstract}

Palavras-chave: Inclusão. Formação Docente. Ensino Regular. Educação Inclusiva. Diversidade.

\begin{abstract}
This article contemplates a bibliographical research in the field of Education, specifically in the area of Special Education, with the objective of understanding how teaching formation in Brazil has been developed from the perspective of inclusive education. Considering these questions, the bibliographical research, counted on theoretical reference of authors like Fernando Becker, Edgar Morin and Boaventura de Sousa Santos. It was also used the historical-cultural perspective of Vygotsky and of authors who dialogue with this approach in order to find in their concepts contribution to the reflections presented here. The study showed that teacher training, both initial and continuing, should be able to produce knowledge aimed at teaching practice that improves responses to meet the demands of the diversity of the students present in the school. The indissociability of theory and practice is the way to train teachers who are capable of critical and reflexive thinking of their pedagogical action and create possibilities to better meet the demands of everyday school life.
\end{abstract}

Keywords: Inclusion. Teacher's Education. Regular Education. Inclusive Education. Diversity. 
O Brasil vive a mais de 20 anos imerso em lutas e discussões intensas sobre o melhor lugar para a escolarização de alunos com deficiências e outras características atípicas de aprendizagem. Atualmente, o nosso país se encontra em um processo de consolidação de leis que garantem o direito à educação de qualidade para alunos público-alvo da Educação Especial no ensino regular no qual as escolas - que não podem negar a matrícula desse alunado - precisam se adaptar para atender as suas necessidades educacionais especiais (BRASIL, 2008, 2011, 2015; entre outros).

O conceito de necessidades educacionais especiais ${ }^{1}$ engloba a especificidade de cada aluno, como também, seu contexto sócio histórico e cultural. Assim sendo, necessidades educacionais especiais são construídas socialmente como produtos de sua interação no (e com) contexto escolar. Portanto, não se trata de uma condição, necessariamente, imutável; podendo ser consideradas demandas em determinado momento ou fase de aprendizagem do sujeito que, posteriormente, podem não ser mais essenciais.

É certo que nem sempre ter necessidades educacionais especiais significa possuir uma deficiência (física, intelectual ou sensorial). Qualquer indivíduo está sujeito em algum momento da sua vida demandar um apoio educacional específico em seu processo de aprendizagem. Para tornar mais claro nosso posicionamento, baseamo-nos no seguinte conceito:

Necessidade educacional especial não é uma característica homogênea fixa de um grupo etiológico também supostamente homogêneo, e sim uma condição individual e específica; em outras palavras, é a demanda de um determinado aluno em relação a uma aprendizagem no contexto em que é vivida (GLAT; BLANCO, 2011, p. 26, grifo original).

À luz do pensamento da teoria histórico-cultural que remete nosso olhar para o indivíduo e suas particularidades, e não mais, para a deficiência em si, não negamos as peculiaridades advindas das questões patológicas das deficiências, mas não tornarmos esse o

\footnotetext{
${ }^{1}$ No decorrer do texto, as expressões alunos com necessidades educacionais especiais, alunos com deficiências e outras condições atípicas de aprendizagem ou alunos público-alvo da Educação Especial - serão utilizados como "sinônimos" mesmo que o conceito utilizado pelo Ministério da Educação (MEC) seja mais restrito do que o empregado aqui.
} 
foco dos apontamentos desse estudo. Nesse contexto, a pesquisa está baseada nos critérios da pesquisa qualitativa e nos fundamentos da perspectiva histórico-cultural de Vygotsky (1993, 1997, 2010), que muito vêm contribuindo para pesquisas na área da Educação e, principalmente, no campo da Educação Especial, como destacado por Hostins, Silva e Alves (2016, p. 160-161):

A contribuição de Vygotski nessa área deve-se à construção de uma abordagem histórico-cultural do desenvolvimento que distingue a linha natural, prejudicada pela deficiência biológica (primária), da linha cultural de domínio de instrumentos socialmente produzidos. Essa última, porque não diretamente vinculada à deficiência, mas ao ambiente social no qual vive o sujeito, é determinante no desenvolvimento das funções psíquicas superiores, construídas em colaboração e essenciais para seu desenvolvimento (HOSTINS, SILVA \& ALVES, 2016, p. 160-161).

O presente artigo buscou compreender como vem acontecendo em nosso país a formação de professores para uma educação inclusiva, quais são as concepções de aprender e ensinar existentes nessa formação e qual a epistemologia do professor que forma estes profissionais para atuar com a diversidade. Para tanto, foi realizada uma pesquisa bibliográfica, "desenvolvida a partir de material já elaborado, constituído principalmente de livros e artigos científicos" (GIL, 2008, p. 50) de diferentes autores que pesquisam no campo da educação e/ou da educação especial e inclusiva.

Gil (2008) ressalta a vantagem de a pesquisa bibliográfica "permitir ao investigador a cobertura de uma gama de fenômenos muito mais ampla do que aquela que poderia pesquisar diretamente" (GIL, 2008, p. 50), visto que compreender, de modo geral, a formação de professores para uma educação inclusiva no país necessita de um leque enorme de fonte de dados. Assim, as informações foram obtidas através de estudos de diferentes autores, tendo os principais conceitos que se relacionam ao tema proposto analisados em profundidade e sendo as teorias e conteúdos interligados cuidadosamente.

De acordo com Gil (2008), “A escolha do problema de pesquisa sempre implica algum tipo de comprometimento" (GIL, 2008, p. 36) e "O problema deve ser formulado como pergunta" (GIL, 2008, p. 38) para focar a pesquisa nos dados e informações necessários na 
busca da (s) resposta (s). Nesse sentido, algumas indagações são valiosas para se pensar a formação docente na perspectiva da educação inclusiva e contextualiza-la a partir da construção do conhecimento e da ausência de consciência dos professores sobre este processo: O que é epistemologia? O que é a inclusão escolar? O que seria uma epistemologia da inclusão? Esse exercício de reflexão é relevante dado que o discurso da inclusão escolar já faz parte do cotidiano dos sistemas de ensino e os professores são os sujeitos que atuam com as mais diferentes especificidades encontradas nas salas de aulas.

Entendendo a epistemologia como ciência e a compreensão da possibilidade do conhecimento, o termo nesse trabalho é designado ao estudo científico da origem, da estrutura, de métodos e da validade do conhecimento e sua relação com o conceito de uma educação para a diversidade. Somos levados a acreditar que não existe "a epistemologia da inclusão", mas que existem diferentes "epistemologias" - ou concepções teóricas - que embasam métodos, metodologias e práticas docentes no processo por uma educação inclusiva, sem que, ao menos, os professores tenham consciência disso.

Seguindo esse pensamento, dentro da ótica de tomada de consciência, Becker (2003, p. 40) considera que

talvez os problemas epistemológicos mais fundamentais sejam o acesso do sujeito ao objeto e a natureza da consciência (...). Como o sujeito vive essa experiência ou como o conhecimento do objeto manifesta-se na consciência do sujeito (BECKER, 2003, p. 40).

O autor, com base nos estudos de Jean Piaget, salienta que só podemos conhecer aquilo sobre o qual agimos, ou seja, temos conhecimento de algo que é o resultado de nossas ações sobre ele, não o objeto de fato. Desse modo, a consciência é um "sistema de significações".

A sociedade é social e historicamente construída pelo homem, necessitando de linguagens plurais para dialogar e interagir com a diversidade. Nesse sentido, a educação reproduz a sociedade e, espera-se da escola, respostas para esta mesma sociedade. Por isso, a urgente necessidade de viabilizar uma prática pedagógica fundamentada na teoria dos 
professores como profissionais autônomos e reflexivos críticos, acreditando que suas práticas pedagógicas podem - e devem - ser constantemente modificadas ou aprimoradas.

Apesar das mudanças nacionais obrigatórias nos currículos dos cursos de Licenciatura, a inclusão escolar como um direito de todos à educação parece ainda não ser realidade. Essa visão necessita ser conhecida por todos os educadores e pela sociedade em geral, para assim ser compreendida e assumida de forma coesa e coletiva.

Desse modo, é preciso um preparo para atuar em situações jamais pensadas durante a formação inicial, para lidar com a diversidade, a incerteza e a complexidade. Segundo Edgar Morin (1996), é preciso uma constante abertura a novas interações e conectar os vínculos do que já se conhece, ampliá-los e transformá-los para melhorar a qualidade de vida.

No texto "Do Pós-Moderno ao Pós-Colonial. E para além de um e outro", Boaventura de Sousa Santos (2004) faz menção aos sinais de uma crise paradigmática, em que o positivismo se apresenta como paradigma e modelo de racionalidade dominante para a ciência (e as ciências sociais). Tendo como base a vivência de um período de transição paradigmática profunda e com a crise do entendimento moderno, surgiram as expressões para a distinção dessa fase de mudança de paradigmas, onde o paradigma dominante, que refletia cada vez menos a práticas científicas da ciência moderna, passaria para o paradigma emergente, designado por Santos como a ciência pós-moderna. Ou seja, essa ciência pós-moderna seria

[...] uma ciência assente numa racionalidade mais ampla, na superação da dicotomia natureza/sociedade, na complexidade da relação sujeito/objecto, na concepção construtivista da verdade, na aproximação das ciências naturais às ciências sociais e destas aos estudos humanísticos, numa nova relação entre a ciência ética assente na substituição da aplicação técnica da ciência pela aplicação edificante da ciência e, finalmente, numa nova articulação, mais equilibrada, entre conhecimento científico e outras formas de conhecimento com o objetivo de transformar a ciência num novo senso comum (SANTOS, 2004, p.4).

Santos (2004) defende que essa nova teoria crítica deve começar pela crítica do conhecimento. E isso só acontece quando o sujeito toma o seu objeto do saber enquanto 
sujeito, como um igual perante seu observador. Dessa maneira, a ação do homem enquanto ser social o faz adotar um conhecimento-emancipação no lugar de um conhecimentoregulação (este último que regula o monoculturalismo e a ação conformista perante o saber) ${ }^{2}$.

No pensamento emancipatório de Boaventura de Sousa Santos uma concepção fundamental é a da experiência social como elemento constitutivo da reinvenção da emancipação. E o autor destaca essa importância visto que duas dimensões da comunidade, participação e solidariedade, são igualmente, negligenciadas por uma modernidade excludente e individualista (HESPANHA, 2002).

Temos que os ideários coloniais já não respondem mais as inquietações geradas na produção de conhecimento, assim como as concepções modernas e pós-modernas dominantes também não proporcionam uma visão geral dentro do processo de globalização e multiculturalismo presentes na contemporaneidade. Ao passo que o desafio é saber como aproveitar a interculturalidade sem o relativismo cultural e epistemológico e, assumindo ainda um posicionamento ético e emancipatório.

Dado o exposto, temos esse novo paradigma sobre o conhecimento, que então, seria uma perspectiva em que o pensamento está em aberto, aquele que está em processo, se fazendo e se constituindo na sociedade e na história. Através da emancipação social, construindo formulações para dar conta do presente, do aqui e agora, para além dos discursos prontos da modernidade ou do pós-modernismo dominante. Tendo o aluno como um ser social e não acadêmico, devemos ter em mente que existe uma grande distância entre a “abertura escolar" e a inclusão escolar.

\section{TEORIA E PRÁTICA}

Ao analisarmos as práticas pedagógicas, o tema que sempre aparece é o da dicotomia que existe entre a teoria e a prática (como se elas fossem coisas totalmente desassociadas). Entretanto, a formação docente é construída historicamente antes e durante o caminho

\footnotetext{
${ }^{2} \mathrm{O}$ conhecimento-regulação seria o impedimento que outras formas de saber contribuíssem para a tentativa de emancipação social, sendo esses saberes e modos de compreensão da realidade deslegitimados pelo conhecimento científico moderno.
} 
profissional do docente, não podendo enfatizar uma em detrimento da outra. No momento em que o professor se apropria do conhecimento e se beneficia de suas contribuições teóricas, ele melhora sua forma de trabalhar e de entender o mundo.

Segundo Becker (1993), o centro do construtivismo (que nada está pronto ou acabado, que o conhecimento se constitui pela interação indivíduo e meio, pelas relações sociais, etc.), sendo este uma postura e não uma técnica ou método, reúne diversas correntes opostas a uma educação tradicional e, majoritariamente, a prática manifestada pelos docentes. Em seus estudos, ele constata que onde ocorre a chamada dicotomia entre teoria e prática, os profissionais tendem a produzir uma prática tradicional de educação. A palavra tradicional por si só não tem um emprego ruim, no entanto, o sentido legitimado de uma educação tradicional é característico de uma educação autoritária e unidirecional.

Nos dias atuais, vemos ainda as implicações da racionalidade técnica, que se tornou uma herança cultural impregnada na mente humana e nas instituições de ensino. Nelas, o professor apenas aplica programas previamente elaborados e limitados por outros especialistas (nem sempre da educação), quase sempre estranhos às práticas educativas encontradas pelos alunos das licenciaturas, por conteúdos formais e cristalizados, currículos que não valorizam a criatividade e a inovação do professor (MEDEIROS; CABRAL, 2006). Para Giroux (1988, p. 23):

As instituições de treinamento de professor e as escolas públicas têm, historicamente, se omitido em seu papel de educar os docentes como intelectuais. Em parte, isto se deve à absorção da crescente racionalidade tecnocrática que separa teoria e prática e contribui para o desenvolvimento de formas de pedagogia que ignoram a criatividade e o discernimento do professor (GIROUX, 1988, p.23).

Deparamo-nos, então, com dois pontos que dialogam e se relacionam entre si: uma cultura profissional marcada pela racionalidade técnica que supervaloriza o conhecimento teórico e o pragmatismo ativista que exclui a formação teórica e a reflexão filosófica. Em virtude do que foi mencionado, como conciliar o que temos aprendido com o que 
encontramos de fato no "chão da escola"? Como aplicar as pesquisas, estudos e teorias à uma realidade tão distinta do que está escrito?

Conforme aponta Becker (2003, p. 45),

\begin{abstract}
Nós não conseguiremos chegar ao aluno e intervir positivamente na sua capacidade de aprender, fazendo treinamentos, modificando técnicas, propondo 'macetes'. Temos que produzir um amplo processo de reflexão epistemológica no qual os 'formadores' se dêem conta de que nada significativo acontecerá enquanto não romperem com as concepções de conhecimento e de aprendizagem que vigoram em nossas escolas (BECKER, 2003, p. 45).
\end{abstract}

É possível apontar algumas considerações a partir do que vivenciamos ainda hoje no ambiente acadêmico universitário e no espaço da escola básica. A formação é diferenciada para aqueles que pretendem seguir carreira acadêmica dentro da universidade e aqueles que irão atuar no ensino básico. Os cursos de formação parecem desenvolver um currículo formal com conteúdo e atividades de estágios distanciados da realidade encontrada nas escolas, não contribuindo para a formação de identidade do profissional docente (MARTINS; NUNES, 2011). Quanto aos cursos de atualização e capacitação dos profissionais em serviço, parecem pouco eficientes para possibilitar o acesso às teorias da educação oferecendo perspectivas de reflexão sobre os contextos vivenciados pelos professores (CARNEIRO, 2006).

Valendo-nos também das contribuições de Morin (2003), "não se pode reformar a instituição sem uma prévia reforma das mentes, mas não se podem reformar as mentes sem uma prévia reforma das instituições" (MORIN, 2003, p. 99). O autor sistematizou "sete saberes" que concentram problematizações e reflexões acerca das necessidades da educação em que categorias, princípios, formulações e proposições pertinentes compõem a teoria da complexidade. A constituição de uma nova racionalidade cientifica social e pedagógica que pede por uma reforma no ensino que ultrapasse o acúmulo de saberes sem ligação um com os outros, algo onde se possa construir redes de saberes necessários à educação atual.

Seja para o professor da escola básica ou para o professor que está formando o professor que irá atuar no ensino de base, o grande problema está em achar que a solução está 
em uma ou em outra. A preocupação com a prática pode tornar um caráter de "mal necessário" à teoria. A prática, tomada como autossuficiente, não passa de técnica. Em um curso de licenciatura ou até em uma formação continuada não será possível ensinar todas as possíveis técnicas de todos os diferentes contextos em que o professor irá se inserir. É preciso privilegiar as duas, teoria e prática. É uma relação includente, e não excludente.

\section{A FORMAÇÃO DOCENTE FRENTE À INCLUSÃO ESCOLAR}

Todas as mudanças concernentes a uma educação inclusiva ao longo desses anos trouxeram como consequência a necessidade de transformar a qualidade do trabalho educacional. O professor do ensino comum, portanto, é um elemento chave para o sucesso dessas modificações por ter o contato direto com o aluno com necessidade educacional especial, no dia a dia da sala de aula. Essa constatação revelou uma grande preocupação com a formação desses professores e, não só dos profissionais que atuam no atendimento especializado.

Voltamos a reafirmar a educação inclusiva como um movimento, não só de ampliação do acesso ao ensino regular por alunos público-alvo da Educação Especial, mas sim, um processo de democratização do ensino no qual existe o respeito as especificidades dos sujeitos, sendo-lhes garantidos os direitos à uma educação emancipatória e de qualidade.

Para a inclusão escolar ter êxito, Capellini e Mendes (2007, p. 123-124) apontam que

[...] deve-se ser considerado um processo e não um evento. Há que ter consideração cuidadosa sobre o que é melhor para a criança, pois nem todas as crianças beneficiam-se inicialmente de todo o tempo na classe comum; planejamento colaborativo cuidadoso, respeitando quantidade de alunos por sala de aula; e de formação em serviço para receber programas colaborativos. A inclusão realmente clama por uma mudança na filosofia e possivelmente uma reestruturação fundamental dos sistemas escolares e das escolas. Isso significa mudanças no currículo, mudanças na prática pedagógica e, especialmente, mudanças na formação dos professores (CAPELLINI; MENDES, 2007, p. 123-124). 
Logo, como já apresentado, a Educação Especial deve atuar como sistema de suporte que a escola comum oferece para atender às necessidades educacionais especiais de seus alunos e contribuir para promover a sua aprendizagem. Assim, como analisa Pletsch (2011), faz-se necessário a garantia de formação inicial e continuada, tempo de interação e planejamento conjunto aos professores que trabalhem com os alunos com deficiências, bem como a todos os profissionais da unidade escolar. A inclusão deve ser entendida e assumida como responsabilidade coletiva de toda comunidade escolar.

Há mais de duas décadas, já eram encontrados indicativos sobre a formação dos docentes para o trabalho com a inclusão escolar. A Portaria 1.793, de dezembro de 1994, exigia sobre "a necessidade de complementar os currículos de formação de docentes e outros profissionais que interagem com portadores de necessidades especiais" (BRASIL, 1994). Alguns anos depois, a Resolução CNE/CP No 1, de 18 de fevereiro de 2002, em seu Art. 3o apontava que

A formação de professores que atuarão nas diferentes etapas e modalidades da educação básica observará princípios norteadores desse preparo para o exercício profissional específico, que considerem:

I - a competência como concepção nuclear na orientação do curso;

II - a coerência entre a formação oferecida e a prática esperada do futuro professor, tendo em vista:

a) a simetria invertida, onde o preparo do professor, por ocorrer em lugar similar àquele em que vai atuar, demanda consistência entre o que faz na formação e o que dele se espera;

b) a aprendizagem como processo de construção de conhecimentos, habilidades e valores em interação com a realidade e com os demais indivíduos, no qual são colocadas em uso capacidades pessoais (BRASIL, 2002).

No artigo $9^{\circ}$ da Resolução $n^{\circ} 4$ de 2 de outubro de 2009 (BRASIL, 2009) está previsto um trabalho colaborativo entre os professores do ensino regular com os professores que atuam nas salas de recursos multifuncionais ou nos Centros de AEE. Propõe-se que esse trabalho deveria ser desenvolvido de forma a articular as atividades do ensino comum, as do 
Atendimento Educacional Especializado, os serviços de saúde e de assistência social. Encontramos no Art. 12 as disposições referentes à formação docente necessária para atuação no Atendimento Educacional Especializado. Segundo esta mesma Resolução, o professor do AEE é responsável por:

I - identificar, elaborar, produzir e organizar serviços, recursos pedagógicos, de acessibilidade e estratégias considerando as necessidades específicas dos alunos público-alvo da Educação Especial; II - elaborar e executar plano de Atendimento Educacional Especializado, avaliando a funcionalidade e a aplicabilidade dos recursos pedagógicos e de acessibilidade; III - organizar o tipo e o número de atendimentos aos alunos na sala de recursos multifuncionais; IV - acompanhar a funcionalidade e a aplicabilidade dos recursos pedagógicos e de acessibilidade na sala de aula comum do ensino regular, bem como em outros ambientes da escola; $\mathrm{V}$ - estabelecer parcerias com as áreas intersetoriais na elaboração de estratégias e nade recursos de acessibilidade; VI - orientar professores e famílias sobre os recursos pedagógicos e de acessibilidade utilizados pelo aluno; VII - ensinar e usar a tecnologia assistiva de forma a ampliar habilidades funcionais dos alunos, promovendo autonomia e participação; VIII - estabelecer articulação com os professores da sala de aula comum, visando à disponibilização dos serviços, dos recursos pedagógicos e de acessibilidade e das estratégias que promovem a participação dos alunos nas atividades escolares (BRASIL, 2009, Art. 13).

Araújo, Rusche, Molina e Carreiro (2010), a partir de pesquisa bibliográfica sobre artigos que analisam a formação de professores, apontam que ainda parece prevalecer uma valorização da formação continuada, mesmo que já exista a preocupação com a formação inicial. Os autores destacam também a presença de ações formativas baseadas em processos de desenvolvimento e aprendizagem da docência, contudo, a racionalidade técnica ainda pode ser encontrada. Por fim, eles relatam que quanto ao processo de formação dos professores sobre a inserção de pessoas com deficiências no ambiente da escola regular, a discussão se mantém de forma generalista.

Um tópico de suma importância relacionado à formação de professores discutido por Fonseca-Janes (2009, p. 69) é que, no Brasil foram extintos quase todos os cursos de 
licenciaturas em Educação Especial destinados ao trabalho com alunos com deficiências ${ }^{3}$. Desse modo,

\begin{abstract}
Muitas instituições de ensino superior, após as deliberações do Conselho Nacional da Educação de 15 de maio de 2006 (BRASIL, 2006), incorporaram na estrutura de suas matrizes curriculares disciplinas intituladas Fundamentos da Educação Inclusiva ou da Educação Especial e titulam seus egressos para trabalhar com pessoas com deficiência na sala de aula regular (FONSECA-JANES, 2009, p. 69).
\end{abstract}

A autora faz uma reflexão sobre a suficiência (ou insuficiência) dessas disciplinas para a formação profissional daqueles que irão trabalhar com os mais diversos tipos de alunado, além das demandas próprias de uma sala de aula do ensino comum. A partir desse questionamento e com os resultados da pesquisa realizada com estudantes de Pedagogia após cursarem disciplina sobre Fundamentos da Educação Inclusiva -, Fonseca-Janes (2009, p. 75) aponta "indicativos de que devemos repensar a formação holística e específica dos pedagogos, sejam eles nos cursos de graduação ou pós-graduação" (FONSECA-JANES, 2009, p.75).

Como Caetano (2009) e Baptista (2006), entendemos que a universidade (tanto pública como privada) necessita provocar seus alunos e futuros professores a refletir sobre situações educacionais que rompam as barreiras do estranhamento, da classificação e dos preconceitos. A escola inclusiva é o espaço de todos, similarmente, os cursos superiores precisam ser espaços de formação para o trabalho com toda a diversidade de sujeitos, assim, como lembra Caetano (2009, p. 72), "traduzir a educação inclusiva das leis, dos planos e intenções para nossa realidade requer produção de conhecimento e prática, tarefa essa da pesquisa científica e, mais especificamente, para as universidades brasileiras" (CAETANO, 2009, p. 72).

\footnotetext{
${ }^{3}$ Atualmente as duas únicas universidades públicas que oferecem curso de licenciatura em Educação Especial são a Universidade Federal de Santa Maria (UFSM), desde 1984, e a Universidade Federal de São Carlos (UFSCar), desde 2009. A formação do especialista em Educação Especial é aceita em níveis de graduação e pós-graduação (lato sensu e stricto sensu). Nessas modalidades, várias instituições de ensino oferecem o curso de especialização na área e muitas várias universidades públicas e privadas oferecem linha ou núcleo de pesquisa específicos em Educação Especial, mas apenas a Universidade Federal de São Carlos possui um Programa de Pós-Graduação em Educação Especial.
} 
A formação continuada, por sua vez, precisa continuar aquilo que já foi, de alguma maneira, visto na formação inicial. Logo, as discussões em torno dos processos de desenvolvimento humano e da diversidade tem que ter espaço nos cursos de graduação de forma contextualizada e levando em consideração as especificidades advindas das mais variadas necessidades educacionais especiais e das deficiências de uma escola que há bem pouco tempo era o lugar de poucos, e não de todos os sujeitos.

De acordo com os resultados encontrados no estudo com os cursos de formação docente em uma universidade do Espírito Santo, Caetano (2009, p. 209) aponta

[...] que é necessário que as questões de discussão sobre a inclusão escolar, independentemente do caráter de formação generalista e/ou especialista, não sejam descoladas do processo de escolarização, da alfabetização, da didática, das questões que tratam do movimento, da Filosofia, da Matemática, dos processos de avaliação da aprendizagem, da pesquisa e da prática pedagógica, da infância, das disciplinas específicas da área (CAETANO, 2009, p. 209).

Segundo Bueno (1999), os professores generalistas são aqueles profissionais considerados os responsáveis pelas classes comuns, formados dessa maneira, reforçando a dicotomia que existiu na educação brasileira: educação comum e educação especial como tipos de educação diferenciados. Os professores considerados especialistas são os docentes capacitados em diferentes necessidades educacionais especiais e responsáveis pelo oferecimento de apoios, suporte, orientação e capacitação aos professores generalistas.

Os cursos de formação para professores especialistas têm que trabalhar para que os futuros docentes sejam vistos como pertencentes ao ambiente escolar e precisam entender que seus conhecimentos de forma descontextualizada e sem articulação dentro da escola não levarão a uma educação de qualidade. Igualmente, as disciplinas presentes nos currículos generalistas de cursos de formação de professores precisam englobar discussões sobre as mais variadas especificidades encontradas na escola. Segundo Bueno, (1999, p. 07):

$\mathrm{Na}$ medida em que a educação inclusiva exige que o professor do ensino regular adquira algum tipo de especialização para fazer frente a uma população que possui características peculiares, ao mesmo tempo exige que 
o professor de educação especial amplie suas perspectivas, tradicionalmente centradas nessas características (BUENO, 1999, p. 07).

Não temos a pretensão de dizer que a formação generalista é a melhor ou que a especialista seria a solução, pois não existe o modelo perfeito de ensinar e/ou aprender. Defendemos, porém, que todo e qualquer espaço de formação docente é lugar do debate da diversidade e da inclusão. Não é mais possível que, em um país que visa uma educação para todos, os cursos de formação inicial continuem alegando que o debate sobre a deficiência é responsabilidade da Educação Especial.

No contexto de educação vigente em nosso país, que continua carente de pessoal qualificado, a formação especialista ainda se faz essencial. Mas, é preciso ter cuidado para que não retorne à visão simplista e clínica centrada na deficiência e não no processo de aprendizagem (CAETANO, 2009).

Abordamos aqui aspectos de grande valia para a formação docente. Por isso, é importante pontuar que, independentemente do nível e tipo de formação, os cursos para professores precisam discutir as necessidades educacionais especiais deixando claro que na diversidade existem especificidades. É sabido que existe diversidade na escola e que demanda um trabalho. Todavia, quando não se discute na prática os caminhos possíveis da escolarização de alunos com deficiência, o conceito de diversidade acaba perdido em seu próprio discurso.

Enquanto ainda estudante, o futuro professor precisa observar em sua formação que o que ele está aprendendo é funcional para os alunos, tanto aqueles que possuem ou não deficiências. Não estamos clamando pela tão falada "receita" de como e quando fazer. Porém, estamos afirmando que quanto mais o indivíduo conhece conceitos, estratégias e recursos para trabalhar com a diversidade do alunado, mais ele poderá criar (ou recriar ou até reproduzir) possibilidades para os alunos de uma escolarização com qualidade.

As mudanças de posicionamento visando uma educação inclusiva não se constituem somente em ações tangíveis, mas também, no discurso e no modo de reflexão/produção de conhecimento. Portanto, não se deve negar aos professores em formação o entrelaçamento 
entre as discussões teóricas e a realidade prática. Eles (e todos nós) precisam entender e acreditar que é possível realizar o trabalho educativo e a inclusão escolar de alunos com deficiência nas salas regulares. E, para tornar isso uma prática constante, precisam ter recebido - e receber constantemente - o embasamento teórico norteador.

Não podemos perder de vista que as concepções que o professor possui fazem parte do tipo de conhecimento que ele construiu a partir de sua formação como aluno e como profissional. Ou seja, o modo como os cursos de formação inicial entendem o trabalho com a diversidade é um ponto crucial na inferência da constituição docente. E mais, tudo isso será refletido de alguma forma no contexto da escola, na relação entre o professor e o aluno e na construção do conhecimento e da aprendizagem.

Algumas pesquisas apresentam diferentes resultados a partir de estudos sobre a formação de professores para o trabalho na perspectiva da inclusão escolar. Menezes (2012), em seu estudo sobre alunos com autismo, destaca o progresso desses estudantes como resultado direto da formação continuada do professor da escola comum. Nos resultados encontrados, a autora aborda a importância dos professores regentes, com o suporte da Educação Especial, conhecer formas diferentes de ensinar e que eles possam avaliar sua pertinência. Dessa forma, segundo a autora, os docentes passam a sentir-se mais seguros em modificar suas práticas e permitem-se experimentar novas formas de ensinar.

No Brasil, alguns estudos sobre a formação docente (CAPELLINI, 2004; ZANATTA, 2004; MOLINA, 2007; CORRÊA, 2008) defendem a necessidade de propor e validar alternativas de assessoria ao professor para lidar com os problemas de comportamento e na promoção de habilidades sociais dos alunos. Em suas conclusões, essa assessoria deve estar articulada à auto avaliação (por meio da ação reflexiva) do professor sobre sua atuação em sala de aula, para assim contribuir com a prática docente.

Segundo as considerações de Mizukami, Reali, Reyes, Martucci, Lima, Tancredi e Mello (2002), a formação do professor tem que ser entendida como um continuum, em que a formação inicial deve contemplar além dos conteúdos básicos, a reflexão na e sobre a ação, para que se possa proporcionar um bom suporte para o exercício da profissão. Já na formação continuada, é necessário repensar o lócus dessa formação, em onde o professor está e, 
considerar e valorizar o saber docente levando em conta a etapa do desenvolvimento profissional de cada um. E, conforme Giesta (2001), a formação continuada do professor se dá num encadeamento de ação e avaliação do ensinar e do aprender.

É comum o discurso de que as escolas e os professores não estão preparados para inclusão. Apesar de não ser de todo falso, esse discurso por si só em nada contribui para a melhoria da educação, da formação ou da organização do contexto e atores escolares. A preparação do professor se dará efetivamente mediante uma formação - e formação também em serviço - que contemple a sua realidade e de seu alunado. Por isso, cursos de formação tem que ir além, trabalhando com o professor no seu dia a dia as necessidades emergentes de sua prática, para o caminhar de ações transformadoras.

Afinal, a educação inclusiva implica em mudança de perspectiva, de concepções educacionais que valorizam a capacidade dos sujeitos, nas construções de conhecimento a partir das relações. O professor é um profissional em construção e cabe aos cursos de formação desses indivíduos garantir a oferta de subsídios teóricos e práticos para proporcionar sujeitos críticos-reflexivos para pensar, criar e recriar estratégias para uma escola inclusiva.

\section{REFLEXÕES FINAIS E QUESTIONAMENTOS OUTROS}

Se o processo de inclusão não vier acompanhado de suportes pedagógicos adequados para o aluno e o professor, se a Educação Especial continuar sendo um sistema paralelo de atendimento e os professores continuarem atuando isoladamente, não alcançaremos a utopia da inclusão escolar: meninos e meninas, com ou sem deficiência aprendendo e convivendo juntos na escola. Ademais, se a formação de professores não for pensada e adequada nos contextos educacionais que vêm se delineando na atualidade continuaremos enfrentando grandes dificuldades para construir efetivamente uma escola democrática e inclusiva (ANTUNES; GLAT, 2011, p.198).

Neste sentido, é fundamental na formação docente discutir a importância e necessidade de uma articulação dos planejamentos e práticas entre professores do Atendimento Educacional Especializado e da classe comum. Afinal, os alunos (com ou sem 
necessidades educacionais especiais) não são responsabilidade de um ou de outro, eles são alunos da escola e, portanto, responsabilidade de todos.

A partir dos pressupostos da coletividade, colaboração e experiência encontrados nas ideias de Vygotsky (1993, 1997, 2010), Hostins, Silva e Alves (2016) abordam que "mais do que estar em uma coletividade, os sujeitos precisam participar ativamente desse grupo" (HOSTINS, SILVA \& ALVES, 2016, p. 161). As autoras dialogam ainda sobre a importância do meio no processo de escolarização e desenvolvimento dos sujeitos, apontando que Vygotsky "procura esclarecer não a predominância do meio sobre o indivíduo, mas a necessária e dialética relação entre eles” (HOSTINS, SILVA \& ALVES, 2016, p. 161).

Corroboramos com os pressupostos da construção do conhecimento, na qual os alunos são sujeitos ativos e que por meio da interação e da interlocução com o outro e pela mediação simbólica, é possível se chegar à aprendizagem. Todavia, no compasso da realidade, algumas indagações emergem: Será que estamos formando professores-mediadores que são capazes de reconhecer as demandas educacionais de seus alunos? Ou ainda estamos formando professores que só conseguem ensinar ao aluno clássico, aquele que aprende de forma linear e que a escola tradicional almeja?

A formação de professores, tanto a inicial como a continuada, deve estar apta para produzir conhecimentos voltados para a prática docente que aprimorem respostas para atender as demandas da diversidade dos alunos presentes na escola. A indissociabilidade da teoria e da prática é o caminho para formar professores capacitados para o pensamento crítico e reflexivo de sua ação pedagógica e criar possibilidades para atender, da melhor maneira, as demandas existentes no cotidiano escolar.

Não adianta ter um modelo único para o atendimento educacional especializado. $\mathrm{O}$ que é preciso, de fato, é a possibilidade ter diferentes suportes que valorizam o direito do aluno no ensino regular, que contribua em sua formação social e acadêmica, que garanta seu acesso aos conteúdos, instrumentos e recursos e que auxiliem em suas relações e interações, quando necessário.

Vislumbramos a construção de uma cultura escolar - e global - que cria um projeto curricular para a educação básica que inclui na sua essência, e isso deve fazer parte da 
dinâmica ordinária da escola. É certo que trabalhar com a individualidade que a Educação Especial preconiza, contraria tudo que a linearidade da escola moderna foi constituída e acredita (MOTTA, 2010). A escola é parte da sociedade que a envolve e, por isso, coexiste com ela e não sozinha. A tão desejada escola inclusiva é possível, mas só teremos uma sociedade inclusiva no dia que não for mais preciso falar sobre inclusão.

Com isso, não estamos defendendo uma realidade escolar utópica, só estamos desejando que a escola - particularmente, a escola pública - seja coerente com o que se prega: uma educação de qualidade para todos. E, a qualidade para todos não é moldar seus alunos em uma mesma forma para que saiam todos iguais, mas sim, garantir o direito do aluno de estar ali até o último ano de escolaridade, ainda que ele não alcance as expectativas que foram pensadas para outros.

É extremamente importante trazer todas essas considerações a respeito das principais questões relativas à formação docente para se trabalhar com e na diversidade de um ambiente inclusivo para entendermos melhor a realidade que nos cerca. A inclusão escolar só é possível no cerne de uma sociedade inclusiva, aquela educação tradicionalista em que o aluno é somente passivo de receber informações já não mais deve fazer parte de uma escola - e de espaços para formação de professores - que se diz inclusiva (OMOTE, 2008; FONSECAJANES, 2009).

Por fim, a educação precisa ser pensada para os alunos, não para tipo ou tipos de alunos, em que todos devem ser entendidos como sujeitos únicos e que, como tais, possuem especificidades. E, quando a formação de professores e a escola deixar de lado o medo do diferente, parando de olhar o outro pelo viés da negação e da impossibilidade, novas configurações serão construídas. É urgente a normalização desse processo, colocar a educação inclusiva como algo que faz parte do projeto da educação básica, independentemente, do aluno com necessidade educacional especial existir ou não. 


\section{REFERÊNCIAS}

ANTUNES, K. C. V.; GLAT, R. Formação de professores na perspectiva da educação inclusiva: os Cursos de Pedagogia em foco. In: PLETSCH, Márcia Denise; DAMASCENO, Allan (orgs.). Educação Especial e Inclusão Escolar: reflexões sobre o fazer pedagógico. Seropédica, RJ: Ed. Da UFRRJ, 2011. p. 188 a 201.

ARAÚJO, M. V.; RUSCHE, R. J.; MOLINA, R.; CARREIRO, L. R. R. Formação de professores e inclusão escolar de pessoas com deficiência: análise de resumos de artigos na base SciELO. Rev. Psicopedagogia, v. 27, n. 84, p. 405-16, 2010.

BAPTISTA, M. A investigação em serviço social. São Paulo: Veras, 2006.

BECKER, F. Ensino e construção do conhecimento: o processo de abstração reflexionante. Porto Alegre. Educação \& Realidade, v. 18, p. 43-52, 1993.

Da ação à operação: o caminho da aprendizagem: J. Piaget e Paulo Freire. Porto Alegre: Palmarinca, 1993.

A origem do conhecimento e a aprendizagem escolar. Porto Alegre: Artmed, 2003.

2003.

Entrevista "Escola e epistemologia do professor". RPD - Revista Profissão Docente,

BRASIL. Portaria $\mathrm{n}^{\circ}$ 1.793/94 - Dispõe sobre a necessidade de complementar os currículos de formação de docentes e outros profissionais que interagem com portadores de necessidades especiais e dá outras providências. 1994.

Resolução CNE/CP No 1, de 18 de fevereiro de 2002. Institui Diretrizes Curriculares Nacionais para a Formação de Professores da Educação Básica, em nível superior, curso de licenciatura, de graduação plena, 2002.

.Política Nacional de Educação Especial na perspectiva da Educação Inclusiva. Brasília, janeiro de 2008.

Resolução $\mathbf{N}^{0}$ 4, de 2 de outubro de 2009. Institui Diretrizes Operacionais para o Atendimento Educacional Especializado na Educação Básica, modalidade Educação Especial. Brasília, 2009.

Decreto $\mathbf{n}^{0}$ 7.611, de 17 de novembro de 2011a. Dispõe sobre a Educação Especial, o atendimento educacional especializado e dá outras providências. DiárioOficial [da] República Federativa do Brasil, Brasília, 18 de nov. de 2011, SEÇÃO, 1, p. 12.

Lei $\mathbf{N}^{0}$ 13.146. Lei Brasileira de Inclusão da Pessoa com Deficiência (Estatuto da Pessoa com Deficiência), 2015.

BUENO, J. G. S. Crianças com Necessidades Educativas Especiais, Política, Educação e a Formação de Professores: Generalistas ou Especialistas? Revista Brasileira de Educação Especial, 1999. 
CAETANO, A. M. A formação inicial de professores na perspectiva da inclusão escolar de alunos com deficiência: o curso de Pedagogia da Universidade Federal do Espírito Santo. 238 f. Tese (Doutorado) - Universidade Federal do Espírito Santo, 2009.

CAPELLINI, V. L. M. F. Avaliação das possibilidades do ensino colaborativo no processo de inclusão escolar do aluno com deficiência mental. 2004. 302f. Tese (Doutorado em Educação Especial) - Programa de Pós-Graduação em Educação Especial, Universidade Federal de São Carlos, São Carlos, 2004.

CAPELLINI, V. L. M. F; MENDES, E. G. O ensino colaborativo favorecendo o desenvolvimento profissional para a inclusão escolar. Educere et educare: Revista de Educação, Cascavel, v. 2, n.4, p. 113-128, jul./dez. 2007.

CARNEIRO R. U. C. Formação em serviço sobre gestão de escolas inclusivas para diretores de escolas de educação infantil. 2006. Tese (Doutorado em Educação Especial) - Programa de PósGraduação em Educação Especial: UFSCar, São Carlos, 2006.

CORREAA, C. I. M. Habilidades sociais e educação: programa de intervenção para professores de uma escola pública. 2008. 140 f. Tese (Doutorado em Educação) - Faculdade de Filosofia e Ciências, Universidade Estadual Paulista, 2008.

FONSECA-JANES, C. R. X. Análise comparativa da percepção dos estudantes do curso de Pedagogia sobre a educação inclusiva. In: MARQUEZINE, M. C. et al (Org.). Re'discutindo a inclusão. Londrina: ABPEE, 2009. p. 21-32.

GIESTA, N. C. Cotidiano Escolar e Formação Reflexiva do Professor: moda ou valorização do saber docente? Araraquara: JM editora, 2001.

GIL, A. C. Métodos e técnicas de pesquisa social. 6. ed. São Paulo: Atlas, 2008.

GIROUX, H. Escola crítica e política cultural. São Paulo: Cortez. 1988.

GLAT, R.; BLANCO, L. M. V. Educação Especial no contexto de uma Educação Inclusiva. In: GLAT, R. (org). Educação Inclusiva: cultura e cotidiano escolar. 2. ed. Rio de Janeiro: 7 Letras, 2011. p. 15-35.

HESPANHA, P. Individualização, fragmentação e risco social nas sociedades globalizadas.Revista Crítica de Ciências Sociais, v. 63, out. 2002.

HOSTINS, Regina Celia Linhares; SILVA, Cristiane de; ALVES, Adriana Gomes.COLETIVIDADE, COLABORAÇÃO E EXPERIÊNCIA: Pressupostos para a inclusão escolar e a aprendizagem de alunos com deficiência intelectual. In: Revista Teias v. 17 •n. 46 • (jul./set. - 2016): Observatórios de Educação Especial e Inclusão Escolar. 2016.

MARTINS, K. O.; NUNES, M. L. A formação docente no curso de Pedagogia. Trabalho de Conclusão de Curso (Graduação em Pedagogia) - Faculdade Católica de Uberlândia, Minas Gerais, 2011.

MEDEIROS, M. V.; CABRAL, C. L. de O. Formação docente: da teoria à prática, em uma abordagem sócio-histórica. Revista E-Curriculum, v. 1, n. 2, jun. 2006. 
MENDES, E. G; VILARONGA, C. A. R; ZERBATO, A. P. Ensino colaborativo como apoio à inclusão escolar: unindo esforços entre educação comum e especial. São Carlos: UFSCar, 2014.

MENEZES, A. R. S. de. Inclusão escolar de alunos com autismo: quem ensina e quem aprende? 2012. 160 f. Dissertação (Mestrado em Educação) - Faculdade de Educação, Universidade do Estado do Rio de Janeiro, Rio de Janeiro, 2012.

MIZUKAMI, M. G. N.; REALI, A. M. M.; REYES, C. R.; MARTUCCI, E. M.; LIMA, E. F.; TANCREDI, R. M. S. P.; MELlO, R. R. Escola e Aprendizagem da Docência: Processos de Investigação e Formação. São Carlos: EDUFSCar, 2002.

MOLINA, R. Avaliação de programas de treinamento de professores para promover habilidades sociais de crianças com dificuldades de aprendizagem. 2007. 185f. Tese (Doutorado em Educação Especial) - Universidade Federal de São Carlos, São Carlos, 2007.

MORIN, E. Ciência com consciência. Rio de Janeiro: Bertrand Brasil, 1996.

A cabeça bem-feita. 5. ed. Rio de Janeiro: Bertrand Brasil, 2003.

MOTTA, M. C. Escola moderna, alunos pós-modernos: como educar. Pernambuco: Editora Unicap, 20 de julho de 2010. Disponível em: Revistas Eletrônicas da UNICAP. Acesso em: 30 ago. 2017.

OMOTE, S. Diversidade, Educação e Sociedade Inclusiva. In: OLIVEIRA, A. A. S.; OMOTE, S.; GIROTO, C. R. M. (orgs). Inclusão Escolar: As Contribuições da Educação Especial. São Paulo: Fundepe Editora, 2008. p. 15-32.

PLETSCH, M. D. A dialética da inclusão/exclusão nas políticas educacionais para pessoas com deficiências: um balanço do governo Lula (2003-2010). Revista Teias, v.12, n. 24, p.39-55, 2011.

SANTOS, B. S. Do Pós-Moderno ao Pós-Colonial. E para além de um e outro. In: CONGRESSO LUSO-AFRO-BRASILEIRO DE CIÊNCIAS SOCIAIS, 7., 2004, Coimbra. Anais... Coimbra, 2004.

VYGOTSKY, L. S. Pensamento e linguagem. São Paulo: Martins Fontes, 1993.

Obras Escogidas V. Madrid: Visor Distribuiciones, 1997.

Quarta aula: a questão do meio na pedologia. Trad.: Márcia Pileggi Vinha. Revisão Max Welcman. Rev. Psicologia USP, São Paulo, v. 21, n. 4, 681-701, 2010.

ZANATTA, E. M. Planejamento de práticas pedagógicas inclusivas para alunos surdos numa perspectiva colaborativa. 2004. Tese (Doutorado em Educação Especial). Universidade Federal de São Carlos. 2004. 